\title{
Infarction in the territory of the medial branch of the posterior inferior cerebellar artery
}

\author{
Pierre Amarenco, Etienne Roullet, Marc Hommel, Pascal Chaine, Rene Marteau
}

\begin{abstract}
We report 10 cases of cerebellar infarction in the territory of the medial branch of the posterior inferior cerebellar artery (mPICA). Axial sections on MRI through the middle of the medulla and the cerebellum showed the infarction as a triangular area with a dorsal base and a ventral apex directed towards the fourth ventricle. The infarct also involved the lateral and dorsal medulla when the mPICA supplied all or part of these regions. Three clinical patterns were observed: 1) pseudolabyrinthine signs with or without dysmetria and ataxia when the medulla was spared; marked axial lateropulsion was present in most cases; 2) complete or incomplete Wallenberg's syndrome, when the medulla was involved; 3) silent infarction. These syndromes are precisely those previously attributed to PICA occlusion without distinction of the branch involved. No alteration of consciousness was recorded and spontaneous recovery was the rule. Cerebellar infarction in the distribution of the mPICA can be regarded as a benign condition with a good prognosis.
\end{abstract}

The posterior inferior cerebellar artery (PICA) sometimes supplies the lateral medullary area. ${ }^{12}$ Its occlusion may then result in Wallenberg's syndrome. ${ }^{34}$ When the PICA does not supply the medulla, its occlusion may lead to a pure vertigo, with or without associated cerebellar signs. ${ }^{5-9}$ Syndromes resulting from the occlusion of the medial or the lateral branch of the PICA have been clarified only in necropsy studies by Goodhart et al ${ }^{10}$ and Amarenco et al. ${ }^{11}$ Given the good prognosis of these infarcts, however, clinico-pathological data may not reflect the true clinical spectrum, necessitating clinicoradiological studies. Computed tomography (CT) and magnetic resonance imaging (MRI) of 10 examples of infarction in the territory of the medial branch of the PICA gave us an opportunity for clinico-anatomical correlation.

After arising from the vertebral artery, the PICA courses transversely and downward along the medulla. It then makes a first caudal loop, ascending in the sulcus separating the dorsal medulla from the tonsil of the cerebellum (fig 1). It then makes a second loop above the cranial part of the tonsil and descends, following the inferior vermis, where it makes a third loop. The common trunk gives rise to a medial branch (mPICA) and a lateral branch at a variable level between the two first loops. ${ }^{12}{ }^{13}$ From pathological data, on an axial mid-medullary and cerebellar section, the mPICA supplies a triangular area with a dorsal base and a ventral apex towards the fourth ventricle (fig 2) ${ }^{14}$ The medial branch of the PICA supplies the inferior vermis (nodulus, uvula, pyramis, tuber and sometimes clivus) and the internal parts of the lobulus semilunaris inferior, lobulus gracilis and tonsil; mPICA exists even when the PICA is hypoplastic. The usual lateral branch of the PICA arises, in this instance, from the anterior and inferior cerebellar artery, ${ }^{15}$ as there is a reciprocal relation between these two arteries. At times the sole medial branch participates in the blood supply of the medulla ${ }^{10}$ in its dorsal region, and sometimes in the lateral retroolivary area. ${ }^{2}$ This latter region is usually supplied by small short circumferential arteries arising from the vertebral artery. ${ }^{1617}$ No correlations between these pathological data and brain imaging are available.

\section{Patients and methods}

Ten cases of cerebellar infarction involving the territory of the mPICA were observed from 1986-89. In all but one (case 7) the diagnosis of cerebellar infarction had been made or suspected on clinical grounds and imaging studies showed involvement of the medial part of the caudal cerebellum. Cases showing abnormality in a larger region than the territory of the medial branch, that is,

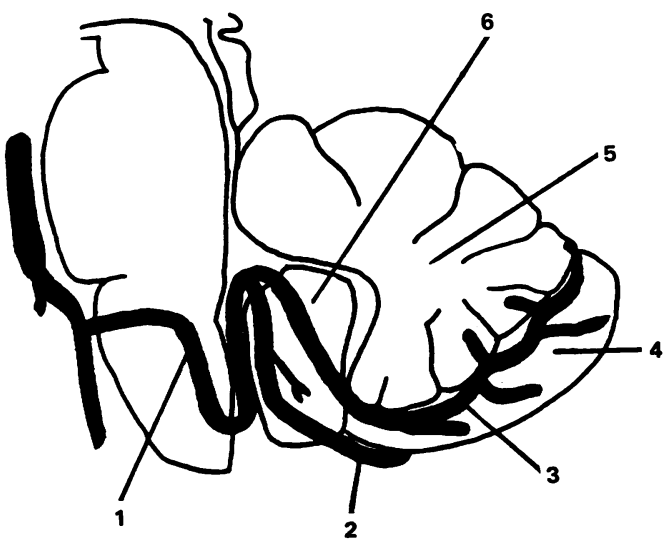

Figure 1 Anatomical drawing of the most frequent course of the posterior inferior cerebellar artery (PICA) and its two main branches. $1, P I C A ; 2$, lateral branch of PICA; 3, medial branch of PICA; 4, internal part of the cerebellar hemisphere; 5 , vermis; 6, cerebellar tonsil. 




Figure 2 Anatomical drawing of the territory of the medial branch of the posterior inferior cerebellar artery (mPICA). 1, cerebellar tonsil; 2, lobulus semilunaris inferior; 3 , vermis (pyramis); 4 , territory of $\mathrm{mPICA}$; 5 , lobulus gracilis; 6 , lobulus biventer. Modified from Amarenco et al ${ }^{11}$. were flexor. Repeated CT scans were normal. MRI, 42 days after onset, showed infarction in the right mPICA territory (fig 4). ECG, echocardiography and ultrasonography of extracranial arteries were normal. On day 13 he became severely confused but this resolved with the correction of moderate hyponatraemia. Three months after the onset the only sequelae were a slightly unsteady gait, right beating horizontal nystagmus and facial pains.

Case 10 was a 55 year old diabetic and hypertensive man who noticed the sudden onset of vertigo (preventing him standing) with dysarthria, nausea and a feeling of imminent death. On admission, two days later, postural vertigo and unsteadiness of gait had persisted. Examination showed right tonic past pointing and left beating horizontal nystagmus. There was neither dysmetria, motor weakness, sensory impairment nor cranial nerve dysfunction. CT and MRI showed infarction in the right

involving the whole territory of the PICA, were excluded. Two cases were proven by CT and eight by MRI. Case 7 was selected on the same radiological criteria without related symptoms or signs. Angiography was performed in only one patient. Cases 8 and 9 were included in the series by Hommel et al..$^{18}$

\section{Results}

Case 3 was an 80 year old hypertensive woman who experienced the sudden onset of vertigo, posterior headache and palpitations. On admission, six hours after the onset, her blood pressure was 160/80. The pulse was 115 and irregular. The vertigo worsened with head movement and improved on recumbency. There was dysmetria of the left superior limb and gaze deviation to the left. Saccades to the right were absent, but oculocephalic responses were preserved. The rest of the neurological examination was normal. A CT head scan was normal. The next day, a T2-weighted MRI showed increased signal in the territory of the left mPICA, sparing the brain stem (fig 3). An electrocardiogram (ECG) showed atrial fibrillation. Echocardiography was normal. The vertigo disappeared a few days later but the patient needed assistance when standing up and walking because of severe axial lateropulsion to the left. Twenty days after the onset of the symptoms the patient was discharged. She was able to walk by herself, ipsilateral gaze and axial lateropulsions had disappeared, but disorders of pursuit eye movements were recorded..$^{19}$

Case 5 was a 76 year old hypertensive man who experienced the sudden onset of vertigo, headache, nausea and difficulty in swallowing. There was right hemiparesis and facial palsy, which lasted a few hours. On admission the next day he had hiccoughs and on the right side dysmetria, paralysis of the ninth and tenth cranial nerves, and hypoaesthesia of the face. There was neither weakness, sensory signs on the left side, oculomotor disturbance or impaired consciousness. Plantar responses
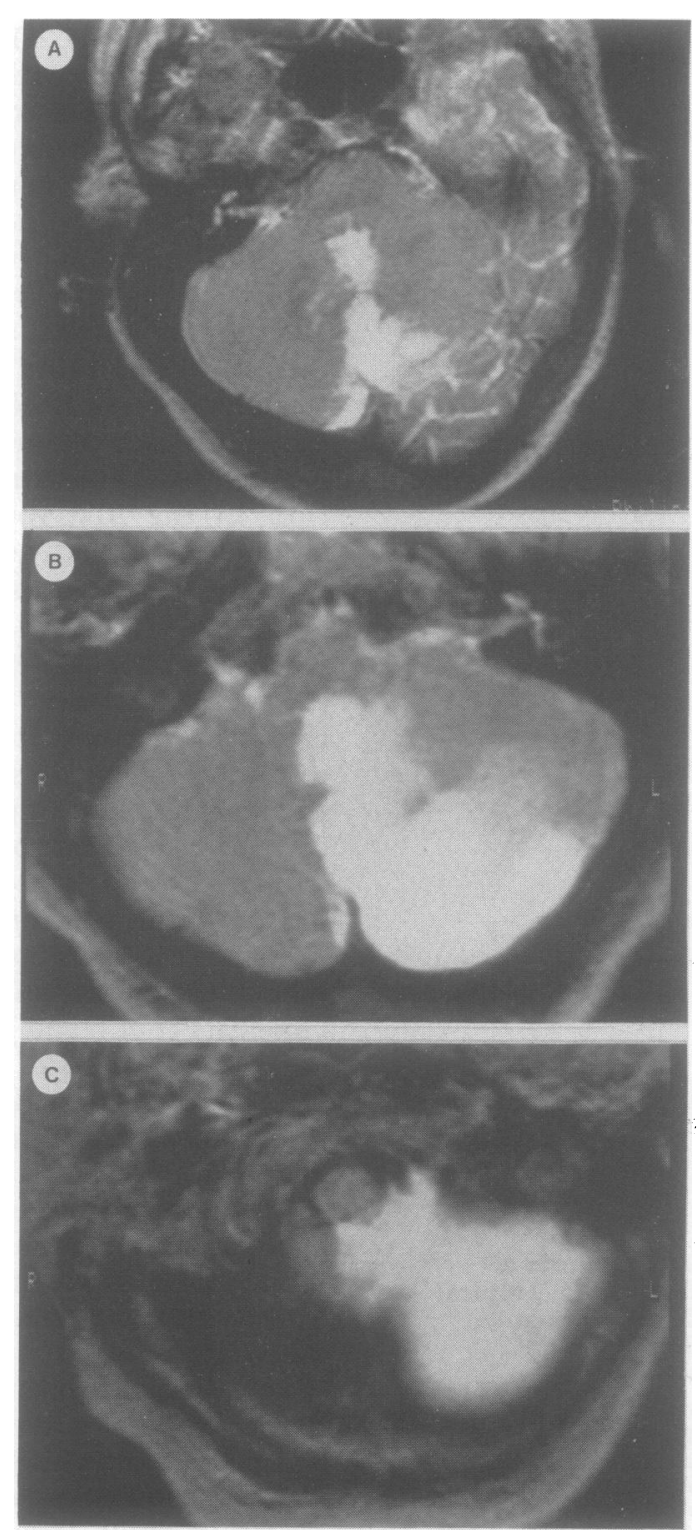

Figure 3 Case 3: Infarction involving the territory of the medial branch of the left PICA in isolation $(a, b, c)$, with a characteristic triangular shape on section through the medulla $(b)$ 


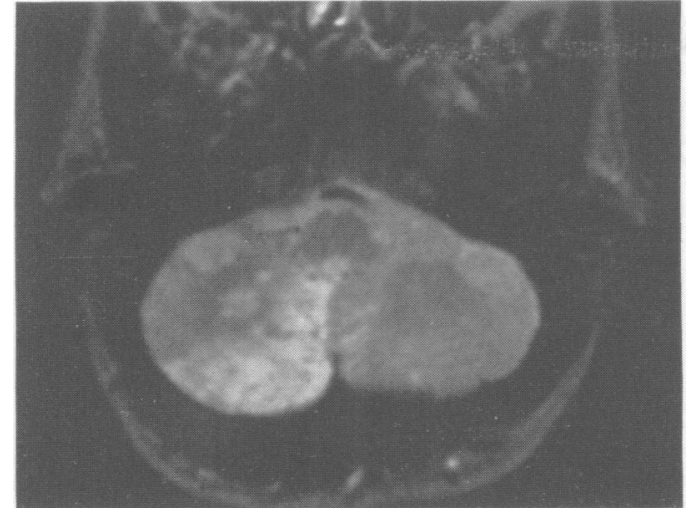

Figure 4 Case 5: Right triangular high signal on T2weighted MRI axial section of the caudal cerebellum.

mPICA territory (fig 5). Angiography showed an occlusion of the right mPICA after its second loop (Fig 5c) as well as severe atherosclerosis of the end of the vertebral arteries and of the basilar artery. The patient spontaneously improved and three weeks after the onset was discharged with residual intermittent dizziness only.

Symptoms and signs of the 10 cases are summarised in table 1 . Symptoms included vertigo (8), nausea or vomiting $(8)$, headache (5) and inability to walk (2). No patient had alteration of consciousness, and spontaneous improvement occurred in all cases. Partial or complete Wallenberg's syndrome was observed in three patients. In six patients there were no signs of medullary involvement; they showed vestibular signs (6), axial lateropulsion (5) or dysmetria (4), either isolated or in association. Silent infarction had occurred in one patient.

On axial MRI sections through the midmedulla, the cerebellar territory of MPICA has a triangular shape (fig 3 to 6 ) and to a larger extent in the lower sections of the cerebellum as shown in case 3 (fig 3a, b, c). Case 8 illustrates an anatomical deviation whereby the contralateral mPICA supplies the vermis and the lobulus semilunaris inferior, taking over the most medial part of the territory usually supplied by the ipsilateral mPICA. ${ }^{141820}$ A good quality CT scan may be necessary to show infarction of this territory illustrated in cases 1 , 2 and 10 (fig 6).

Infarction was probably due to cardiac embolism in three cases: two had paroxysmal and one chronic atrial fibrillation. Angiography (one case) showed occlusion of the right mPICA after its second loop (Fig 5c) due to either atherosclerotic or cardiac embolism. The stroke mechanism remained undetermined in six other cases.

\section{Discussion}

To our knowledge there are no reports concerning the territory of the MPICA on MRI, ${ }^{21}$ nor
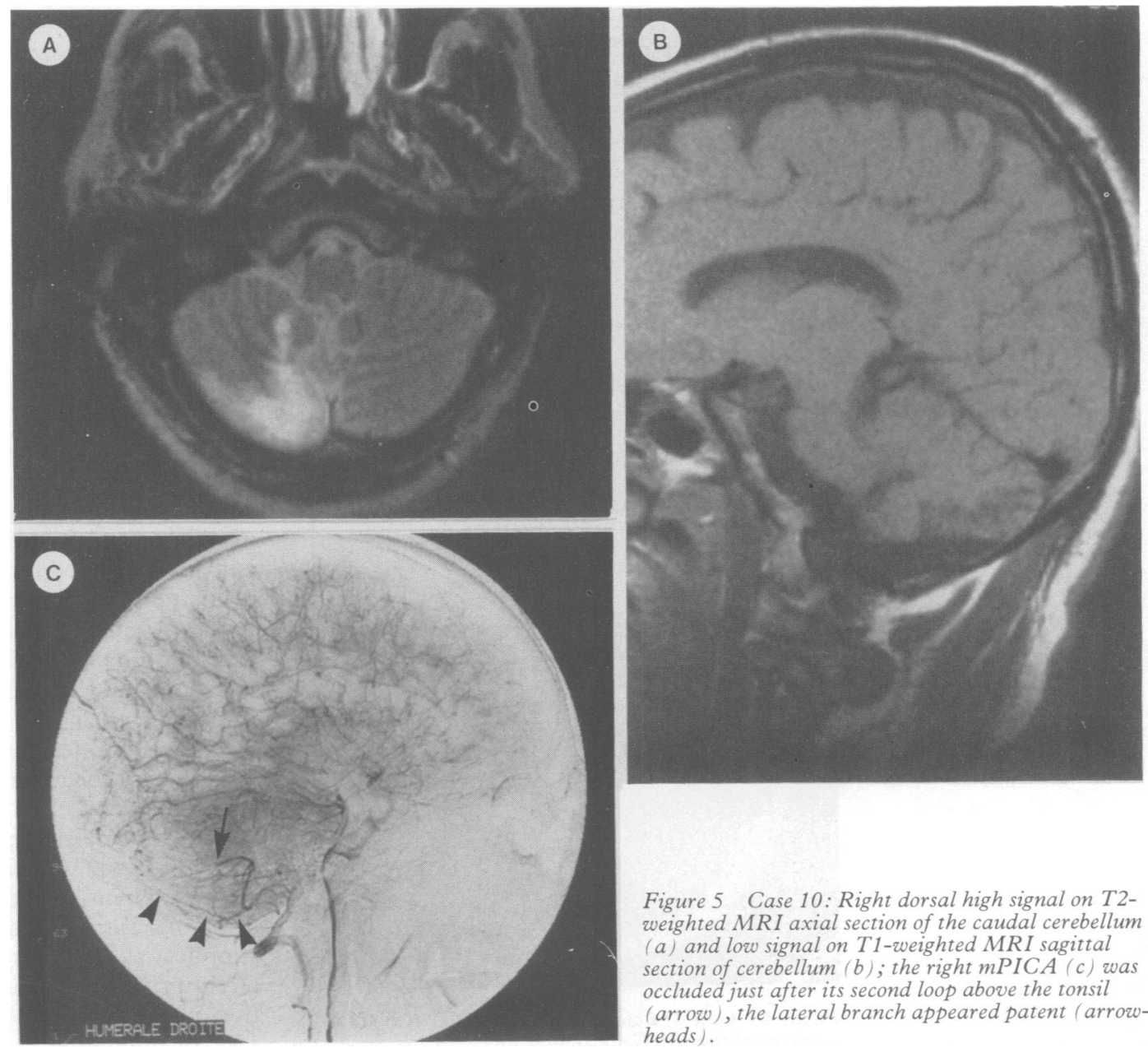

Figure 5 Case 10: Right dorsal high signal on T2weighted MRI axial section of the caudal cerebellum (a) and low signal on T1-weighted MRI sagittal section of cerebellum (b); the right $\mathrm{MPICA}(c)$ was occluded just after its second loop above the tonsil (arrow), the lateral branch appeared patent (arrowheads). 
Table Infarcts of the medial branch of the posterior inferior cerebellar artery

\begin{tabular}{|c|c|c|c|c|}
\hline Author, year & Age, sex & Symptoms at onset & Signs & $\begin{array}{l}\text { Source } \\
\text { diagnosis }\end{array}$ \\
\hline $\begin{array}{l}\text { Goodhart et al, } 1936 \\
\text { (Case 1) }\end{array}$ & 64/Male & Dizziness, inability to walk & Wallenberg's syndrome & Necropsy \\
\hline Fisher et al, 1963 (Case 2) & 66/Female & Necropsy finding & & Necropsy \\
\hline $\begin{array}{l}\text { Duncan et al, } 1975 \\
\text { (Case 1) }\end{array}$ & 78/Male & Vertigo & Nystagmus & Necropsy \\
\hline \multicolumn{5}{|l|}{ Amarenco et al, 1989} \\
\hline (Case 6028) & 78/Male & Vertigo & & Necropsy \\
\hline (Case 5193) & 53/Male & Vertigo, vomiting & Wallenberg's syndrome & Necropsy \\
\hline (Case 4001) & 71/Male & $\begin{array}{l}\text { Vertigo, vomiting, headache, } \\
\text { inability to walk }\end{array}$ & Wallenberg's syndrome & Necropsy \\
\hline (Case 4419) & 61/Female & Vertigo, facial numbness & $\begin{array}{l}\text { Wallenberg's syndrome } \\
\text { Wallenberg's syndrome }\end{array}$ & $\begin{array}{l}\text { Necropsy } \\
\text { Necropsy }\end{array}$ \\
\hline (Case 4417) & 58/Female & Overshadowed by other neurc & cal disorder & Necropsy \\
\hline (Case 3399) & 66/Female & Overshadowed by other neurc & cal disorder & Necropsy \\
\hline (Case 3368) & 64/Male & Necropsy finding & & Necropsy \\
\hline (Case 5705) & 75/Male & Necropsy finding & & Necropsy \\
\hline \multicolumn{5}{|l|}{ Present series } \\
\hline (Case 1) & 43/Male & $\begin{array}{l}\text { Vertigo, vomiting, headache, } \\
\text { inability to walk }\end{array}$ & $\begin{array}{l}\text { Ipsilateral axial lateropulsion, } \\
\text { mild dysmetria }\end{array}$ & CT \\
\hline (Case 2) & 78/Male & Inability to walk & Ipsilateral axial lateropulsion & CT \\
\hline (Case 3) & $80 /$ Female & $\begin{array}{l}\text { Vertigo, vomiting, posterior } \\
\text { headache }\end{array}$ & $\begin{array}{l}\text { Ipsilateral axial lateropulsion, } \\
\text { mild dysmetria, gaze } \\
\text { deviation }\end{array}$ & MRI \\
\hline (Case 4) & 73/Female & $\begin{array}{l}\text { Vertigo, vomiting, posterior } \\
\text { headache }\end{array}$ & $\begin{array}{l}\text { Ipsilateral axial lateropulsion, } \\
\text { mild dysmetria }\end{array}$ & MRI \\
\hline (Case 5) & 76/Male & $\begin{array}{l}\text { Vertigo, vomiting, posterior } \\
\text { headache }\end{array}$ & $\begin{array}{l}\text { Incomplete Wallenberg's } \\
\text { syndrome }\end{array}$ & MRI \\
\hline (Case 6) & 25/Male & $\begin{array}{l}\text { Vertigo, vomiting, posterior } \\
\text { headache }\end{array}$ & $\begin{array}{l}\text { Ipsilateral axial lateropulsion, } \\
\text { dysmetria }\end{array}$ & MRI \\
\hline (Case 7) & 45/Female & MRI finding. & & MRI \\
\hline (Case 8) & 51/Female & Vertigo, vomiting & Wallenberg's syndrome & MRI \\
\hline (Case 9) & 57/Male & $\begin{array}{l}\text { Vertigo, vomiting, posterior } \\
\text { headache }\end{array}$ & Wallenberg's syndrome & MRI \\
\hline (Case 10) & 55/Male & Vertigo, nausea, dysarthria & $\begin{array}{l}\text { Unilateral vestibular } \\
\text { syndrome }\end{array}$ & MRI \\
\hline
\end{tabular}

of any case with anatomical demonstration of mPICA occlusion and corresponding infarction. Goodhart and Davison ${ }^{10}$ reported a case of infarction in the dorsal area of the medulla, without involvement of the cerebellar lobules, but described mPICA occlusion as "incomplete". In a pathological study of 28 cases of infarction in the territory of the PICA ${ }^{11}$ two of the authors of this study observed nine cases with infarction of the medial part of the caudal cerebellum in a triangular pattern, consistent with the anatomical distribution of the mPICA $;{ }^{20}$ there were, however, no cases with mPICA occlusion. Angiographic confirmation of mPICA occlusion was shown in one case of the present series (case 10, fig 5c). Our MRI and CT anatomical findings correlate well with the pathological data previously reported. ${ }^{11} \mathrm{It}$ may therefore be assumed that the arterial territory involved in our 10 cases was that of the mPICA, with its typical triangular shape (fig 2).

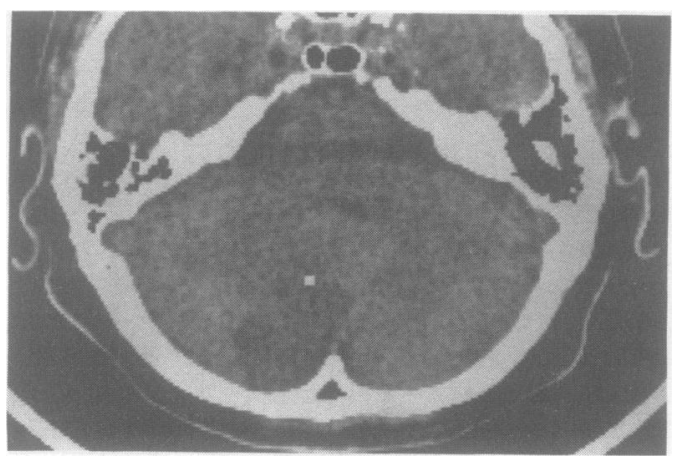

Figure 6 Case 1: Low density area on CT lying in the territory of the $\mathrm{MPICA}$.
Table 1 compares the symptoms and signs observed in our patients with those of the pathological reports of infarctions in the mPICA territory from the literature. ${ }^{151011}$ Cases with Wallenberg's syndrome were less frequent in the present series than cases without signs of medullary involvement. Vertigo and vestibular signs were the most prominent clinical features. At times they occurred alone mimicking a labyrinthine lesion, as previously reported. ${ }^{5611}$ In each of these cases, however, there was at least one symptom or sign which led to the diagnosis such as posterior headache, slight dysarthria or horizontal (rather than horizonto-rotatory) nystagmus. Normal caloric responses and direction-changing nystagmus on gaze to each side or after changing the posture of the head or decubitus are two other signs which have been described in "pure" vestibular involvement of PICA infarcts. 58

The most striking clinical finding was an axial lateropulsion which prevented orthostatism and persisted long after the disappearance of the tonic vestibular deviation. In our case 2 it was isolated. In case 3 an ipsilateral lateropulsion of gaze was added to vertigo and axial lateropulsion. In all cases it was the last sign to improve. Such a lateropulsion has been observed in lesions involving thalamus, ${ }^{22}$ medulla ${ }^{23}$ or the anterolateral part of the rostral cerebellum. ${ }^{24-26}$

Thus two clinical patterns can be distinguished. 1) First, Wallenberg's syndrome, which occurs when medullary signs overshadow cerebellar signs. This occurs when the mPICA supplies all or part of the lateromedullary territory. It has been estimated that an infarction in the territory of the mPICA occurs in $13 \%$ of Wallenberg's syndrome. ${ }^{11} 2$ ) Secondly, 
a syndrome consisting of vertigo, vestibular signs, dysmetria, ataxia, and axial lateropulsion, isolated or in association, which occurs when the medulla is spared. These two syndromes have been previously attributed to occlusion of the main trunk of the PICA. ${ }^{45}$ Our findings suggest that they could be due to the sole occlusion of the medial branch of the PICA. However, silent infarct (present in five out of the 12 pathological cases and one out of our 10 patients) may also occur. No differences were found in brain imaging between the two clinical patterns and the case with silent infarct. In two of the three infarcts with Wallenberg's syndrome, MRI showed a lateral medullary infarct.

On the other hand, the clinical syndromes resulting from occlusion of the lateral branch of the PICA are not known. No clinical reports are available in the literature. Two pathological series relating to infarction in the PICA territory and its branches reported six cases of involvement of the lateral branch of the PICA (case 4 from Goodhart et al ${ }^{10}$ and five cases from Amarenco et $a l^{11}$ ). All cases were confounded by other neurological disorders or were chance necropsy findings. This suggests that the involvement of this part of the cerebellum may be clinically silent.

Our series also points out that embolism is a not uncommon cause. ${ }^{11}$ Neither hydrocephalus nor fatal outcome occurred. This could be explained by the small territory supplied by the mPICA, that is, by the small extent of the resulting infarction. According to Sypert and Alvord ${ }^{27}$ more than one third of the cerebellum must be involved by the infarct before oedema leads to coma and death. Thus, cerebellar infarction in the distribution of the mPICA may be regarded as a benign condition with a good prognosis.

We are indebted to Professor J Lapresle and to Dr D Malapert for permission to use clinical data from their patients (cases 1 and 7) and Doctor Bryan Youl for his invaluable help with the English.

1 Fisher CM, Karnes WE, Kubick CS. Lateral medullary infarction: the pattern of vascular occlusion. JNeuropathol Exp Neurol 1961;20:323-79.
2 Duvernoy HM. Human brainstem vessels. Berlin: SpringerVerlag, 1978.

3 Wallenberg A. Acute bulbäraffection (Embolie der art cerebellar post inf sinistr?). Arch F Psychiatr 1895;27: cerebellar

4 Wallenberg A. Anatomischer befund in einem als "Acute bulbäraffection (Embolie der art cerebellar post inf sinistr?)" beschriebenem falle. Arch F Psychiatr 1901;34: 923-59.

5 Duncan GW, Parker SW, Fisher CM. Acute cerebellar infarction in the PICA territory. Arch Neurol 1975;32:364-8.

6 Guiang RL, Ellington OB. Acute pure vertiginous dysequilibrium in cerebellar infarction. Eur Neurol 1977;16:11-5.

7 Feely MP. Cerebellar infarction. Neurosurgery 1979;4:7-11.

8 Samson M, Mihout B, Thiebot J, Segong G, Weber J, Proust B. Forme bénigne des infarctus cérébelleux. Rev Proust B. Forme benigne des in

9 Huang CY, Yu YL. Small cerebellar strokes may mimic labyrinthine lesions. J Neurol Neurosurg Psychiatry 1985;48:263-5.

10 Goodhart SP, Davison C. Syndrome of the posterior inferior cerebellar arteries and of anterior inferior cerebellar arteries and their branches. Arch Neurol Psychiatry 1936;35:501-24.

11 Amarenco P, Hauw JJ, Hénin D, et al. Les infarctus du territoire de l'arteré cérébelleuse postéro-inférieure. Etude clinico-pathologique de 28 cas. Rev Neurol (Paris) 1989;145:277-86.

12 Margolis MT, Newton TH. The posterior inferior cerebellar artery. In: Newton MT, Poots TH, eds. SaintLouis: CV Mosby. Radiology of the skull and brain angiography 1974;68:1710-74.

13 Taveras JM, Wood EH. Diagnostic neuroradiology Vol II. Baltimore: Williams and Wilkins. 1976:783-7, 793-6.

14 Amarenco $P$, Hauw JJ. Anatomie des artères cèrèbelleuses. Rev Neurol (Paris) 1989;145:267-76.

15 Amarenco P, Hauw JJ. Cerebellar infarction in the territory of the anterior and inferior cerebellar artery. A clinicopathological study of 20 cases. Brain 1990;113:139-55.

16 Ramsbottom A, Stopford JSB. Occlusion of the PICA. Br Med J 1924;1:364-5.

17 Hauw JJ, Der Agopian P, Trelles L, Escourolle R. Les infarctus bulbaires. Etude systématique de la topographie infarctus bulbaires. Etude systematique de la topograph

18 Hommel M, Pollak P, Gaio JM, et al. Imagerie par résonance magnétique et infarctus latérobulbaire. Rev Neurol (Paris) 1988;144:272-8.

19 Pierrot-Desseilligny Ch, Amarenco P, Roullet E, Marteau R. Vermal infarct with pursuit eye movement disorders. $J$ Neurol Neurosurg Psychiatry (in press).

20 Lazorthes G. Vascularisation et circulation cérébrales. Paris: Masson. 1961.

21 Savoiardo M, Bracchi M, Passerini A, Visciani A. The vascular territories in the cerebellum and brainstem: CT and MR study. AJNR 1987;8:199-209.

22 Masdeu JC, Gorelick PB. Thalamic astasia: inability to stand after unilateral thalamic lesions. Ann Neurol 1988;23: after unilate.

23 Babinski J, Nageotte J. Hémiasynergie, latéropulsion et myosis bulbaire. Nouv Iconog de la Salpêtrière 1902; 15:492-512.

24 Ranalli PJ, Sharpe JA. Contrapulsion of saccades and ipsilateral ataxia: a unilateral disorder of the rostral cerebellum. Ann Neurol 1986;20:311-6.

25 Kase CS, White JL, Joslyn JN, Williams JP, Mohr JP. Cerebellar infarction in the superior cerebellar artery distribution. Neurology 1985;35:705-11.

26 Bogousslavsky J, Régli F. Latéro-pulsion axiale isolée lors d'un infarctus cérébelleux flocculo-nodulaire. Rev Neurol (Paris) 1984;140:140-4.

27 Sypert GW, Alvord EC. Cerebellar infarction. A clinicopathologic study. Arch Neurol 1975;32:357-63. 